\title{
Real-Time Observation of Atomic Layer Deposition Inhibition: Metal Oxide Growth on Self-Assembled Alkanethiols
}

\author{
Jason R. Avila, ${ }^{\dagger}$ Erica J. DeMarco, ${ }^{\dagger}$ Jonathan D. Emery, $^{\dagger}$ Omar K. Farha, ${ }^{\dagger, \S}$ Michael J. Pellin, ${ }^{\ddagger}$ \\ Joseph T. Hupp, ${ }^{\dagger}$ and Alex B. F. Martinson* ${ }^{*}+$ \\ ${ }^{\dagger}$ Department of Chemistry, Northwestern University, 2145 Sheridan Road Evanston, Illinois 60208, United States \\ ${ }^{\ddagger}$ Material Science Division, Argonne National Laboratory, 9700 S Cass Avenue, Lemont, Illinois 60439, United States \\ ${ }^{\S}$ King Abdulaziz University, Faculty of Science, Department of Chemistry, Jeddah, Saudi Arabia
}

\section{Supporting Information}

\begin{abstract}
Through in situ quartz crystal microbalance (QCM) monitoring, we resolve the growth of a self-assembled monolayer (SAM) and subsequent metal oxide deposition with high resolution. We introduce the fitting of mass deposited during each atomic layer deposition (ALD) cycle to an analytical island-growth model that enables quantification of growth inhibition, nucleation density, and the uninhibited ALD growth rate. A long-chain alkanethiol was self-assembled as a monolayer on goldcoated quartz crystals in order to investigate its effectiveness as a barrier to ALD. Compared to solution-loading, vapor-loading is observed to produce a SAM with equal or greater inhibition ability in minutes vs days. The metal oxide growth temperature and the choice of precursor also significantly affect the nucleation density, which ranges from 0.001 to 1 sites $/ \mathrm{nm}^{2}$. Finally, we observe a minimum 100 cycle inhibition of an oxide ALD process, $\mathrm{ZnO}$, under moderately optimized conditions.
\end{abstract}

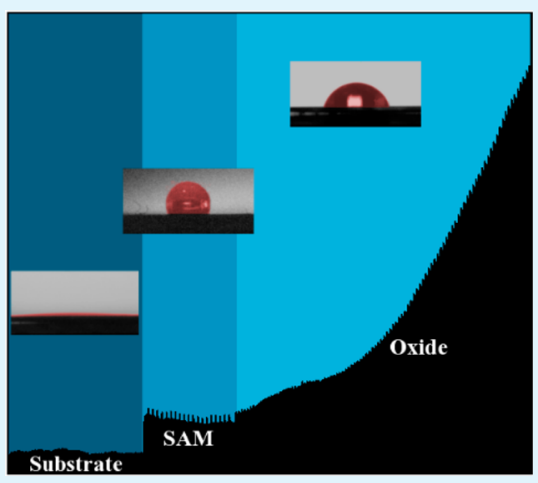

KEYWORDS: atomic layer deposition, self-assembled monolayers, quartz crystal microbalance, alkanethiol, in situ, analytical methods

\section{INTRODUCTION}

Atomic layer deposition (ALD) is a versatile route to the precise and conformal growth of oxides, nitrides, sulfides, and pure metals. ${ }^{1-3}$ In contrast to physical deposition methods this surface synthetic method is grounded in well-defined surface chemistry, which affords the opportunity for self-limiting and precise deposition. Furthermore, the chemical specificity of ALD surface reactions should allow, in theory, ${ }^{4}$ for selective substrate attachment. For example, the rapid reaction of a specific metal precursor with one surface-termination (e.g., hydroxyl) may be severely inhibited or even excluded with another (e.g., alkane). However, perhaps in part due to the aggressive, and therefore unselective, chemistry of some of the most popular ALD precursors (e.g., trimethylaluminum), this prospect remains largely unrealized. Although ALD science has made remarkable strides in depositing uniformly everywhere, there is great room for improvement in selective, inhibited growth. Although several ALD processes that are inherently slow to nucleate (e.g., Pt, Ru, Ir) have been further slowed, ${ }^{5-11}$ a significant inhibition in metal oxide growth beyond 50 ALD cycles has not been demonstrated.

The most prevalent and successful route to chemically inhibiting ALD growth at the nanometer scale is through selfassembled monolayers (SAMs). ${ }^{3,7}$ Long-chain alkyl silanes $^{6-8,12-14}$ are most commonly employed, sometimes lithographically using conventional stamping techniques. Although applicable to a wide range of hydroxyl-terminated substrates and modestly effective against a variety of metal- organic $\mathrm{ALD}$ precursors, the $\mathrm{RSiX}_{3}$ ( $\mathrm{X}=\mathrm{Cl}$ or alkoxy) inhibition layers still leave much to be desired. A large delay to the onset of standard growth rates is typically only observed for $\mathrm{Ru}$ and $\mathrm{Pt}^{6,7}$ Although $\mathrm{RSiX}_{3}$ has been shown to delay normal $\mathrm{Pt}$ and $\mathrm{Ru}$ growth for over 100 cycles, ${ }^{6,9}$ there is a dearth of reported "hold-off" values greater than 50 cycles for metal oxide growth using any SAM. ${ }^{15,16}$

Achieving a chemical route to area-selective growth will require new characterization methods that probe the precise failure modes of SAM inhibition layers at the scale of the mechanisms responsible. In an X-ray photoelectron spectroscopy (XPS) study toward this end, Bent and co-workers examined the extent of cluster formation after ALD on alkyl silane SAM layers. ${ }^{7}$ By varying the solution loading time and length of the SAM, they observed that the nucleation of $\mathrm{HfO}_{2}{ }^{15,16}$ and $\mathrm{Pt}$ nucleation ${ }^{10}$ islands depends on SAM "quality" (i.e., packing density). Spatial nucleation densities of $0.01 \mathrm{~nm}^{-2}$ after 50 cycles of $\mathrm{Pt}^{10}$ have been achieved under optimized conditions. For reference, an uninhibited and facile ALD processes such as TMA alternately dosed with $\mathrm{H}_{2} \mathrm{O}$ to grow $\mathrm{Al}_{2} \mathrm{O}_{3}$ shows "nucleation densities" of $\sim 8 \mathrm{~nm}^{-2} \cdot{ }^{17}$ However, to date the nucleation density of $\mathrm{HfO}_{2}$ or other ALD-grown oxides over SAMs has yet to be quantitated. We

Received: August 9, 2013

Accepted: July 10, 2014

Published: July 21, 2014 


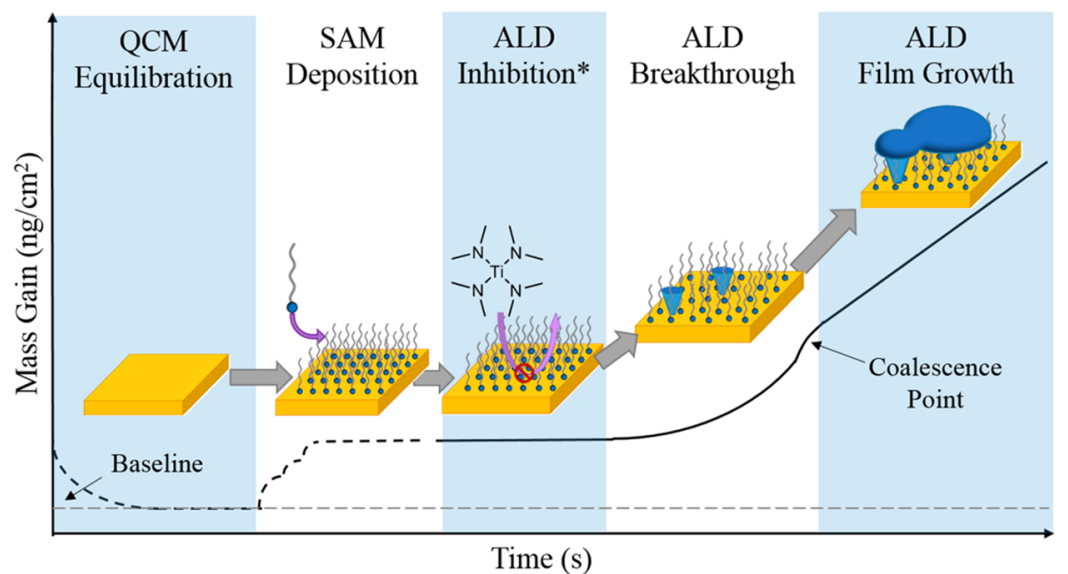

Figure 1. Idealized in situ QCM trace illustrating system equilibration and SAM treatment (dark dashed line) followed by ALD cycling (solid line). An analytical model will be fit to the ALD breakthrough and film growth regions. *In many cases, defects in the SAM layer result in the absence of a phase in which inhibition is nearly complete.

aim to seed this discussion and provide a high-throughput path to quantitation.

Metal oxide surfaces are the most common platform for ALD growth, likely owing to their good stability, wide applicability, and easy generation by common ALD processes. However, elemental metal substrates are equally interesting, with applications that range from solar energy conversion to integrated circuits. ${ }^{3}$ In addition, metals form the basis for some of the most conceptually ideal SAMs-alkanethiols on Au, $\mathrm{Ag}, \mathrm{Cu}$ and $\mathrm{Pt} .{ }^{18}$ These platforms may provide the opportunity to study the mechanism of ALD inhibition on an especially well-defined surface termination as well as the possibility to identify chemistry capable of more uniform and complete inhibition. To the best of our knowledge, the model alkanethiol SAM system has been examined only as a means of blocking trimethylaluminum on $\mathrm{Au}^{19,20}$ and $\mathrm{Ir} \mathrm{ALD}$ on $\mathrm{Cu}$ surfaces ${ }^{11}-$ but only at low (below $100{ }^{\circ} \mathrm{C}$ ) and high $\left(250{ }^{\circ} \mathrm{C}\right)$ temperatures, respectively, with both characterized strictly ex situ.

Ex situ characterization of the microscopic nucleation events under study here are inherently limited by the contrast and resolution of the island growth that reveals SAM "breakthrough”. As an alternative method, we offer a quartz crystal microbalance (QCM) study to probe ALD nucleation in situ and more precisely infer the inhibition afforded by SAMs. By applying an alternating current to a quartz crystal, an oscillation is induced, the frequency of which is governed by the crystal itself as well as any mass added via deposition. When appropriately implemented, this method allows for detection of mass change with $\mathrm{ng} / \mathrm{cm}^{2}$ precision-a level that corresponds to approximately $1 / 30$ th of one continuous monolayer of lowmass metal oxide growth by ALD. ${ }^{17,21}$ As with many in situ measurements, the challenge here is to provide a precisely controlled experiment (in this case an ideal SAM-terminated surface) with sufficient throughput to deduce meaningful trends from variable process conditions. The primary barriers here are the long setup time of a traditional QCM fixture as implemented in an ALD tool (4+ hours) combined with a lack of facile ALD processes to regenerate the desired metal surface in situ. To surmount these barriers, we instead utilize a wall-mounted QCM design ${ }^{22}$ that allows for relatively rapid exchange and equilibration of a fresh Au-coated quartz crystal, i.e., less than $45 \mathrm{~min}$. This capability provides a unique opportunity to study "ALD inaccessible" surfaces like $\mathrm{Au}$, which is ideal for SAM growth but has been impractical for ALD QCM implementation. Using the wall-mounted QCM, we probe in situ for the first time the effectiveness of a model alkanethiol SAM as an inhibition layer against metal oxide ALD. We implement and assess the suitability of an island growth model to quantitate the eventual growth breakthrough. Reasonable fits to this model allow quantitation of the nucleation density under a variety of process conditions. A departure from the simple island model is, however, observed in the case of $\mathrm{ZnO}$ ALD where at least 100 standard ALD cycles are inhibited after an unanticipated initial mass addition.

\section{EXPERIMENTAL SECTION}

Materials and Preparation. Solvents and 1-dodecanethiol $\left(\mathrm{C}_{12} \mathrm{SH}\right)$ were obtained from Sigma-Aldrich and used as received. Prior to SAM deposition, AT and RC-cut quartz crystals (Colnatech) were rinsed with acetone and then isopropanol before being blown dry under flowing $\mathrm{N}_{2}$. The crystals were then exposed to a stream of $8 \%$ ozone in oxygen for $10 \mathrm{~min}$. Less extensive cleaning led to water contact angles greater than 5 degrees. For solution $\mathrm{C}_{12} \mathrm{SH}$ loading, the quartz crystals were immersed into a $10 \mathrm{mM}$ solution of $\mathrm{C}_{12} \mathrm{SH}$ in ethanol for $18-52 \mathrm{~h}$, followed by a thorough ethanol rinse before being blown dry under flowing $\mathrm{N}_{2}$. For vapor loading, the $\mathrm{C}_{12} \mathrm{SH}$ was heated to $105{ }^{\circ} \mathrm{C}$ for delivery from a standard ALD precursor cylinder (Swagelok, $50 \mathrm{~mL}$ ). Metal-organic ALD precursors tested in this study included trimethylaluminum (TMA, Sigma-Aldrich), diethylzinc (DEZ, Sigma-Aldrich), tetrakis(dimethylamido)titanium (TDMATi, Strem Chemical Inc.), and tetrakis(dimethylamido)tin (TDMASn, Strem Chemcial Inc.). TDMATi and TDMASn were heated to 75 and $40{ }^{\circ} \mathrm{C}$, respectively. Millipore water (18M $\Omega$, Milli-Q system) was used for ALD and contact angle measurements.

ALD Instrumentation. Measurements were carried out in a Savannah 200 ALD reactor (Cambridge Nanotech, Inc.). The lid was modified as previously reported ${ }^{22}$ to accommodate two QCM crystals that are oscillated by a commercial thin-film deposition monitor (Inficon, SQM-160). Figure 1 shows an idealized QCM trace of the SAM loading and metal-oxide deposition on a clean Au-coated quartz crystal. Each trace can be conceptually separated into two parts: crystal preparation (dashed line) and metal oxide ALD process cycling (solid line). Crystal preparation includes thermal equilibration of the crystal $^{22}$ and in some cases in situ SAM growth. QCM crystals were equilibrated at the reactor temperature and under vacuum for $\sim 45 \mathrm{~min}$ to ensure optimal thermal stability and full desorption of any physisorbed contaminants. Vapor-phase SAM growth was performed under continuous $\mathrm{N}_{2}$ flow $(20 \mathrm{sccm})$ with a conventional half-cycle pulse-purge sequence $\left(t_{1}-t_{2}\right)$ where $t_{1}$ is the $\mathrm{C}_{12} \mathrm{SH}$ pulse $(1 \mathrm{~s})$ and $t_{2}$ 
is the purge time $(60 \mathrm{~s})$. As the SAM layer self-assembles on the $\mathrm{Au}$ surface we expect to observe a saturating mass gain that approaches that of a close-packed $\mathrm{C}_{12} \mathrm{SH}$ film $-230 \mathrm{ng} / \mathrm{cm}^{2} .{ }^{23}$ Unless stated otherwise, 20 consecutive half-cycles of $\mathrm{C}_{12} \mathrm{SH}$ were used to prepare all vapor-deposited films. When vapor loading is utilized, there is a seamless transition to metal oxide ALD cycling (solid line) without vacuum break. A conventional metal oxide deposition "AB cycle" sequence was used $\left(t_{1}-t_{2}-t_{3}-t_{4}\right)$ where $t_{1}$ is the pulse time for the metal precursor, $t_{3}$ is the pulse time for water, and $t_{2}$ and $t_{4}$ are the purge times for the metal precursor and water, respectively. Pulse times $\left(t_{1}\right.$ and $\left.t_{3}\right)$ for DEZ, TMA, and water were $15 \mathrm{~ms}$, whereas that for TDMATi and TDMASn $\left(t_{1}\right)$ was $150 \mathrm{~ms}$. All processes have ALD windows of at least $100-175^{\circ} \mathrm{C}$ and in all cases we have used standard dose times and purge times $\left(30 \mathrm{~s}\right.$ for experiments $<150{ }^{\circ} \mathrm{C}, 20 \mathrm{~s}$ for $\geq 150{ }^{\circ} \mathrm{C}$ ) for metal oxide processes as optimized by the tool manufacturer and verified in our lab. ${ }^{24,25}$ Metal oxide ALD cycling on SAM surfaces may result in a period of virtually no growth, a period of slow deposition that results from island growth, and finally a period of "standard"/uninhibited ALD at a rate equal to conventional thin film growth. As idealized in Figure 1, the in situ QCM may provide access to a wealth of information to better understand SAM deposition, metal oxide ALD blocking (complete inhibition/"hold off"), island nucleation and growth, as well as film coalescence-at which point island growth transitions to conventional continuous film growth over any remaining SAM. To fully interpret and quantify the wealth of information accessible in each QCM trace, we attempt to fit each mass gain trace to an analytical ALD island growth and coalescence model.

Analytical Model. To quantify the degree of inhibition by the SAM, we attempt to fit the mass versus cycle data provided by the QCM to an ALD island growth model developed by Nilsen and coworkers. ${ }^{26}$ The model rigorously defines island growth during an ALD process using a limited set of assumptions, summarized here. First, a regular hexagonal array of nucleation sites with spatial density $\left(N_{\mathrm{d}}\right)$ is assumed to form only during the first ALD cycle. This assumption is necessary to significantly simplify the interpretation of growth and its appropriateness will be evaluated later. Three dimensional, hemispherical growth off of these nucleation sites is posited to occur in subsequent cycles. ${ }^{26}$ The hemispheres grow with a constant thickness per cycle $(\Delta r)$ that is equal to the intrinsic (thin film ALD) thickness added during each cycle. Once the hemispheres, of radius $r$, grow beyond their radius of convergence $\left(R_{\text {cov }}\right)$, they coalesce into a slightly roughened but continuous thin film. Equation 1 (detailed in the Supporting Information) defines the total mass predicted $\left(\mu_{\mathrm{m}}\right)$ after each ALD cycle number $(n)$ in two distinct regimes-prior and subsequent to island coalescence.

$$
\mu_{\mathrm{m}}\left(N_{\mathrm{d}}, \Delta r\right)=\left\{\begin{array}{c}
\text { island growth; } r<R_{\mathrm{cov}} \\
\text { continuous film growth; } r \geq R_{\mathrm{cov}}
\end{array}\right.
$$

In the first regime, $\mu_{\mathrm{m}}$ is simply the product of the hemisphere volume and the material density (d), or $(2 / 3) N_{\mathrm{d}} \pi r^{3} d$, where $r$ is equal to $n \Delta r$. The spatial density of island growth $\left(N_{\mathrm{d}}\right)$ can then be converted to a radius of convergence $\left(R_{\text {cov }}\right)$, the radius at which the islands coalesce to a continuous film. The overall effect of this growth model is an exponentially increasing mass deposited in each subsequent cycle as the island surfaces grow, followed by an abrupt attenuation in slope when the islands converge and the sidewall area is reduced (see Figure 1). It should be noted, however, that this feature will be washed out in real systems to the extent that the nucleation sites are randomly (vs hexagonally) positioned, resulting in a distribution of cycle numbers at which islands converge.

\section{RESULTS AND DISCUSSION}

SAM Characterization and Durability. The range of feasible and optimal growth temperatures for the ALD of various metal oxides varies widely depending on both precursor chemistry $^{1,27}$ and desired film properties. ${ }^{28,29}$ Therefore, temperature stability will be an important factor when determining the usefulness of a SAM for inhibiting growth of any particular ALD process. The most commonly reported temperatures for oxide growth are between 100 and $250{ }^{\circ} \mathrm{C}$. Therefore, we investigate the inhibition efficacy of alkanethiol SAMs as a function of substrate temperature over this range. The $N_{\mathrm{d}}$ of $\mathrm{TiO}_{2} \mathrm{ALD}$ on quartz crystals, loaded with $\mathrm{C}_{12} \mathrm{SH}$ from solution for $18 \mathrm{~h}$, reveals a strong temperature dependence above $150{ }^{\circ} \mathrm{C}$, Figure 2 .

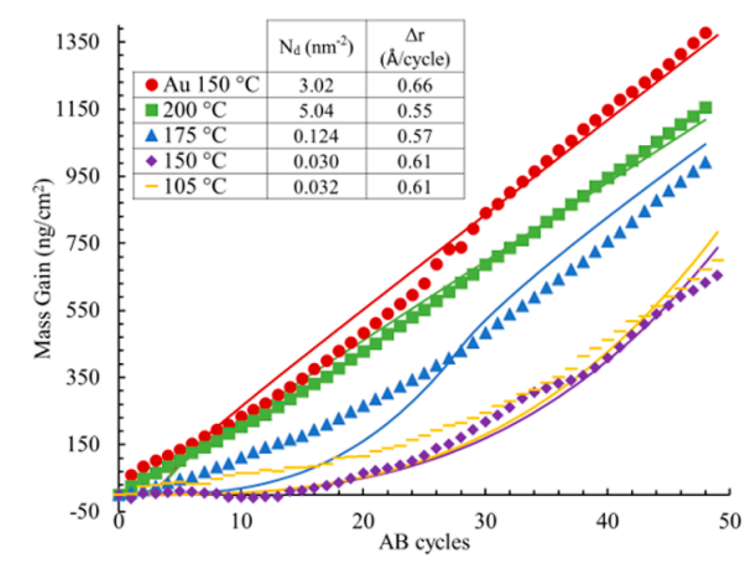

Figure 2. $\mathrm{TiO}_{2}$ mass deposited versus ALD cycle number as a function of substrate temperature. Au-coated QCM crystals are solution-loaded with $\mathrm{C}_{12} \mathrm{SH}$ for $18 \mathrm{~h}$. Note that the intrinsic growth rate $(\Delta r)$ naturally varies slightly with the inverse of reactor temperature for this ALD system. An ex situ ellipsometric determination of $\Delta r$ for the $\mathrm{TiO}_{2} \mathrm{ALD}$ process revealed a normal growth rate of $0.6 \AA /$ cycle at $150{ }^{\circ} \mathrm{C}$.

Even by eye, the inhibition of $\mathrm{TiO}_{2} \mathrm{ALD}$ on $\mathrm{C}_{12} \mathrm{SH}$ on $\mathrm{Au}$ is clear. At 105 and $150{ }^{\circ} \mathrm{C}$ the inhibition is most pronounced and clearly significant even when compared to a nominally bare $\mathrm{Au}$. Previous XPS studies of ozone-cleaned elemental Au surfaces reveal a finite presence of $\mathrm{O}$ atoms that is exceedingly difficult to exclude which may account in part of the $\mathrm{TiO}_{2}$ nucleation that we observe. ${ }^{30}$ Fitting the raw data to the island growth model proposed results in modest fits that reproduce the known growth rate for this ALD $\mathrm{TiO}_{2}$ process. The data recorded at $150{ }^{\circ} \mathrm{C}$ is particularly well fit with the exception of a small oscillation around 37 cycles that can be traced to a temperature deviation to which the quartz crystal oscillation is also sensitive. At $105{ }^{\circ} \mathrm{C}$, our RC-cut quartz crystals are even more sensitive to small $\left(<1{ }^{\circ} \mathrm{C}\right)$ temperature deviations, ${ }^{22}$ resulting in additional artifacts. However, the overall trend with substrates temperature is clear. At temperatures less than 150 ${ }^{\circ} \mathrm{C}$ an $N_{\mathrm{d}}$ of $\sim 0.03 \mathrm{~nm}^{-2}$ is fit that implies one nucleation site every $\sim 33 \mathrm{~nm}^{2}$ on average. The lack of a clear inflection point prior to linear growth suggests a largely random distribution of nucleation sites in this system. However, from the $\mathrm{N}_{d}$ value we can estimate an $R_{\text {cov }}$ of $3.26 \mathrm{~nm}$, which indicates coalescence occurs on average around the 59th cycle, which is beyond the bounds of Figure 2 . At both 105 and $150{ }^{\circ} \mathrm{C}$, less than a single cycle of growth-equivalent $\left(23 \mathrm{ng} / \mathrm{cm}^{2}\right)$ is deposited within the first 10 ALD cycles. The data are consistent with a growth model that assumes all nucleation events occur during the first ALD cycle. At $175{ }^{\circ} \mathrm{C}$ the inhibition effect is already compromised as revealed by a significantly larger $N_{\mathrm{d}}$ value $\left(0.124 \mathrm{~nm}^{-2}\right)$ relative to lower temperature experiments. This is visualized as a much earlier and more significant addition of mass. The fit also notably deviated from experiment, suggesting the possibility of an alternative mechanism at play. At $200{ }^{\circ} \mathrm{C}$ $N_{\mathrm{d}}$ is more than 2 orders of magnitude greater than at the 
lowest growth temperatures and is on par with the nucleation density of the bare Au control. These temperature effects are not surprising, given recent studies by Rodriquez and coworkers, in which alkanethiol SAMs are observed to chemically fracture around $\sim 177{ }^{\circ} \mathrm{C}$ due to cleavage of the $\mathrm{C}-\mathrm{S}$ bond of the SAM layer. ${ }^{31}$ Upon cleaving of the $\mathrm{C}-\mathrm{S}$ bond, the surface will likely be terminated by $\mathrm{S}-\mathrm{H}$ functionalities. These sites may serve as superior nucleation sites relative to a bare $\mathrm{Au}$ surface and thereby begin to explain a slightly larger $N_{d}$ observed at $200{ }^{\circ} \mathrm{C}$ compared to the Au control. Although $\Delta r$ is larger in the Au control (the $\mathrm{TiO}_{2} \mathrm{ALD}$ growth process is faster at lower temperatures ${ }^{32}$ ) the linear growth region that results from island coalescence is achieved within fewer cycles, confirming the trend observed by model fitting for $\mathrm{N}_{\mathrm{d}}$. This study suggests that alkanethiol SAMs are a promising approach to oxide ALD inhibition but that oxide ALD processes with growth temperatures windows that extend to less than $175{ }^{\circ} \mathrm{C}$ are the best candidates for area-selective ALD with this class of SAM.

Solution-Deposited SAM Layers. The most common practice for depositing a SAM onto a given substrate, for application in ALD or otherwise, is through solution soaking. ${ }^{23}$ In some previous applications of area-selective ALD, the solution loading was patterned by a stamping material (e.g., PDMS ). ${ }^{3,12,18}$ Soaking times in excess of $12-18 \mathrm{~h}$ are typically needed to create a dense and stable film, ${ }^{7}$ whereas some reports suggest an organized layer is not complete until 7-10 days. ${ }^{23}$ There are, however, few reports examining the effect of solution loading time on the inhibition of metal oxides $\mathrm{ALD}^{15}$ and no information with respect to $\mathrm{ZnO}$ on alkanethiols specifically. Figure 3 reveals the effect of $\mathrm{C}_{12} \mathrm{SH}$ solution loading time on the inhibition of $\mathrm{ZnO}$ ALD.

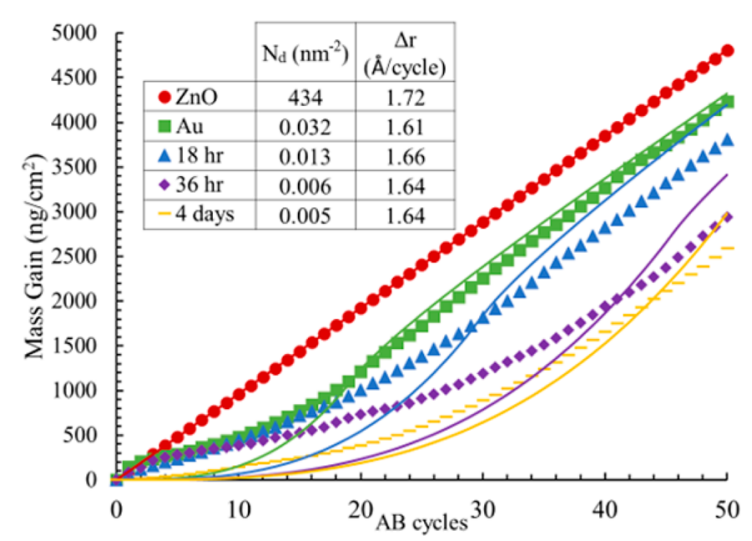

Figure 3. Growth of $\mathrm{ZnO}$ at $150{ }^{\circ} \mathrm{C}$ on $\mathrm{C}_{12} \mathrm{SH}$-coated $\mathrm{Au}$ QCM crystals. $\mathrm{C}_{12} \mathrm{SH}$ was loaded for $18 \mathrm{~h}$ (blue triangles), $36 \mathrm{~h}$ (purple diamonds), and 4 days (yellow dashes). Growth of $\mathrm{ZnO}$ on bare $\mathrm{Au}$ (green squares) and previously $\mathrm{ZnO}$-coated QCM crystals (red circles) are included as controls. An ex situ ellisometric determination of $\Delta \mathrm{r}$ for this $\mathrm{ZnO} \mathrm{ALD}$ process revealed a normal growth rate of 1.7 $\AA /$ cycle.

Two control experiments are considered first-that of $\mathrm{ZnO}$ $\mathrm{ALD}$ initiation on bare $\mathrm{Au}$ and on $\mathrm{ZnO}$ itself. It is clear from the nonlinear QCM trace that ZnO ALD is partially inhibited on a clean Au surface. However, the mass added per cycle is not well fit by this nucleation model. Although some unintentional surface oxygen are almost certainly present, we expect a relatively small number of surface hydroxyls- the surface chemistry by which $\mathrm{DEZ} / \mathrm{H}_{2} \mathrm{O}$ grows $\mathrm{ZnO}^{1,33}$ - such that low nucleation density is not surprising and has been previously inferred. ${ }^{31}$ Again, nominally bare $\mathrm{Au}^{34}$ surfaces have previously been shown to almost always include significant surface oxygen as determined by XPS investigations under various preparation conditions. ${ }^{30}$ Therefore, the nucleation density may depend on the reactivity of each particular metal precursor with surface oxygen contaminants. In contrast, the $N_{\mathrm{d}}$ for $\mathrm{ZnO}$ on itself is best fit by any value over $\sim 10 \mathrm{~nm}^{-2}$, which corresponds to an $R_{\text {cov }}$ that is less than the $r$ expected after only a single cycle of $\mathrm{ZnO}$. This is equivalent to saying that the deposition does not occur in an island-growth mode but as a continuous film. The fit for deposition on bare Au shows a much lower $N_{\mathrm{d}}$ of $\sim 0.03$ $\mathrm{nm}^{-2}$; however the data are not well fit by this model. Instead, the QCM traces of bare Au and SAM-coated substrates show a significant mass gain at early cycle numbers that remains relatively constant for a period not predicted by the island growth model (refer to Figure S2 in the Supporting Information for a zoom-in view of the QCM trace in Figure 3). Although the long-term growth of $\mathrm{ZnO}$ is significantly perturbed by SAM treatment, as shown in Figure 3, the initial mass uptake during early ALD cycles, shown in Figure S2 in the Supporting Information, indicates nucleation is not completely eliminated. One possible explanation for this behavior is that nucleation sites are present at relatively high density, but that after initial reactivity, further growth at these sites is inhibited by the surrounding SAM. We speculate that this behavior, in contrast to that observed with $\mathrm{TiO}_{2}$, may result from the short alkane chain present on diethylzinc, which may align with the long-chain alkanethiol to form a kind of hybrid self-assembled monolayer that is resistant to additional deposition. This possibility is further described later in the discussion. We refer to this slowing of normal ALD growth as "inhibition" in contrast to "hold-off", which we deem a subset of inhibition that excludes any metal oxide deposition. Regardless, forming a $\mathrm{C}_{12} \mathrm{SH}$ SAM over $18 \mathrm{~h}$ does inhibit $\mathrm{ZnO}$ ALD growth relative to the bare $\mathrm{Au}$ control. Even by eye, SAM loading for $36 \mathrm{~h}$ produces a still greater improvement in multicycle inhibition. Even greater inhibition is achieved by loading for 4 days, yielding a crudely approximated value for $N_{\mathrm{d}}$ that is $\sim 3$ times less than that induced by a bare Au surface. Although these studies reveal the $\mathrm{C}_{12} \mathrm{SH} \mathrm{SAM}$ on $\mathrm{Au}$ to also be an effective inhibitor of $\mathrm{ZnO}$ growth, the deposition appears to occur according to an unconventional nucleation mechanism that includes significant uptake in the first few cycles. Unfortunately, a 4+ day SAM deposition time is largely impractical for most applications.

Vapor-Loading SAMs. Given the relatively high vapor pressure of many SAM-forming molecules, the vapor-phase loading of SAMs is well documented. ${ }^{23}$ With easy implementation of elevated temperatures and long exposures, vapor-phase SAM formation can be faster and more complete than via liquid-phase. ${ }^{23}$ The delivery of alkane-silanes and alkanethiols in standard ALD tools has been previously reported, ${ }^{11,35}$ with all the potential benefits of a vapor-phase loading process in addition to an air-free and temperature-stable transition to ALD growth. ${ }^{31}$ Here, we investigate the vaporization and SAM growth of alkanethiols within an ALD reactor. An additional benefit of the in situ QCM study implemented here is that it provides a view of the saturation kinetics of vapor-loaded SAM formation. Several $1 \mathrm{~s}$ "mini-doses" of $\mathrm{C}_{12} \mathrm{SH}$ are pulsed into the tool repeatedly until no additional mass is added. This procedure should indicate the point at which a complete SAM is achieved with the caveat that the final (and in some cases 
most important ${ }^{16}$ ) stage of SAM densification is expected to produce a vanishing small mass change that exceeds the sensitivity limits of our QCM. As such, the QCM presents a convenient way to roughly optimize SAM uptake, the rate of which is expected to depend on the size of each $\mathrm{C}_{12} \mathrm{SH}$ exposure as well as reactor temperature. A representative SAM saturation trace, Figure S3 in the Supporting Information, reveals that the alkanethiol SAM is largely complete after $\sim 2$ doses of $1 \mathrm{~s}$ each. Each $1 \mathrm{~s}$ pulse of $\mathrm{C}_{12} \mathrm{SH}$ shows a partial pressure of $\sim 300$ mTorr above the $\mathrm{N}_{2}$ baseline for a total exposure of $\sim 10^{5}$ Langmuir. This is comparable to the exposure determined to yield a film of maximum coverage and packing density for other SAM vapor loading techniques. ${ }^{31}$ An average maximum uptake in our experiments was $213 \mathrm{ng} / \mathrm{cm}^{2}$, which approaches the maximum theoretical coverage of $\sim 230 \mathrm{ng} / \mathrm{cm}^{2}$ for an $\mathrm{Au}$ (111) surface when assuming an S-C angle of $28^{\circ} .^{23}$ Contact angle measurements and ellipsometry (see Figure S4 in the Supporting Informaiton) also suggest a packing density close to the theoretical limit on $\mathrm{Au}$ witness substrates (thermally deposited $\mathrm{Au}$ on $\mathrm{Si}$ ). A typical contact angle was $110^{\circ}$ and an ellipsometric thickness of $\sim 8 \AA$ was observed after $60 \mathrm{C}_{12} \mathrm{SH}$ doses. Overall, we find that compared to solution loading, vapor-phase loading of alkanethiols is an equally or more reliable and efficient route to dense SAM formation. A corresponding improvement in inhibition for solution- and vapor-loaded crystals is illustrated in Figure 4 , where the $N_{\mathrm{d}}$ that results after $\mathrm{ALD}$ of $\mathrm{TiO}_{2}$ at $150{ }^{\circ} \mathrm{C}$ for each method is roughly equivalent despite a loading time difference of $\sim 1000 \times$.

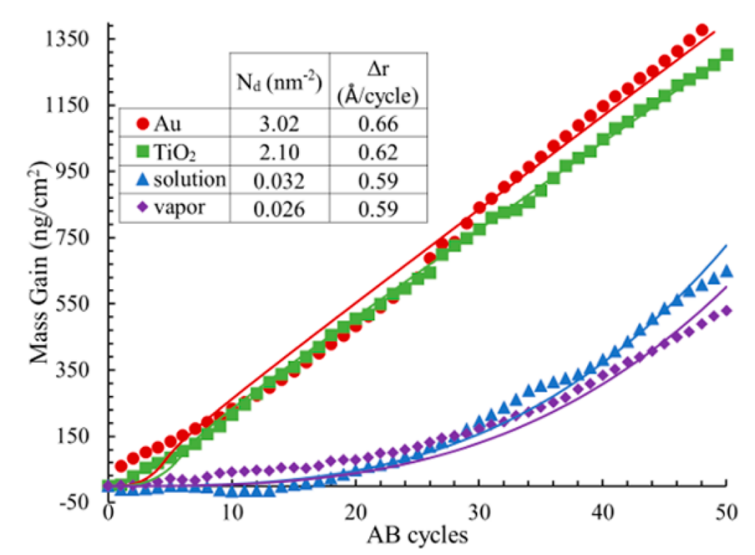

Figure 4. $\mathrm{TiO}_{2}$ ALD growth on various QCM crystal SAM preparations at $150{ }^{\circ} \mathrm{C}$. Bare $\mathrm{Au}$ (red circles) and $\mathrm{TiO}_{2}$ coated $\mathrm{Au}$ (50 mini-doses, green squares) show little to no inhibition. $\mathrm{C}_{12} \mathrm{SH}$ vapor- (purple diamonds) and solution-loaded (18 h, blue triangles) crystals produce significantly lower nucleation densities.

Like solution-loaded SAM substrates, vapor-loaded substrates inhibit $\mathrm{TiO}_{2} \mathrm{ALD}$ in a way that is well fit by the island growth model, again ignoring small deviations induced by small temperature excursions in the crystal. In both cases, an $\mathrm{N}_{\mathrm{d}}$ comparable to those previously reported for Pt ALD over an optimized alkylsilane SAM $\left(0.01 \mathrm{~nm}^{-2}\right)^{10}$ is deduced from the model.

Inhibition of Additional ALD Oxide Processes. Even under identical and optimal SAM loading conditions, we observe the inhibition of different ALD process to vary greatly. Furthermore, the island growth model invoked here does not always capture the dynamics of mass deposition, as in the case of $\mathrm{ZnO}$. We hypothesize that any finite chemical reactivity with the SAM, trace physisorption, or unimolecular gas-phase decomposition may result in inadequately modeled mass addition due to deviation from the model assumptions. We observe a wide range of SAM-induced inhibition upon investigation of several common oxide ALD processes at 125 ${ }^{\circ} \mathrm{C}$, most of which fit well to the island growth model, Figure 5.

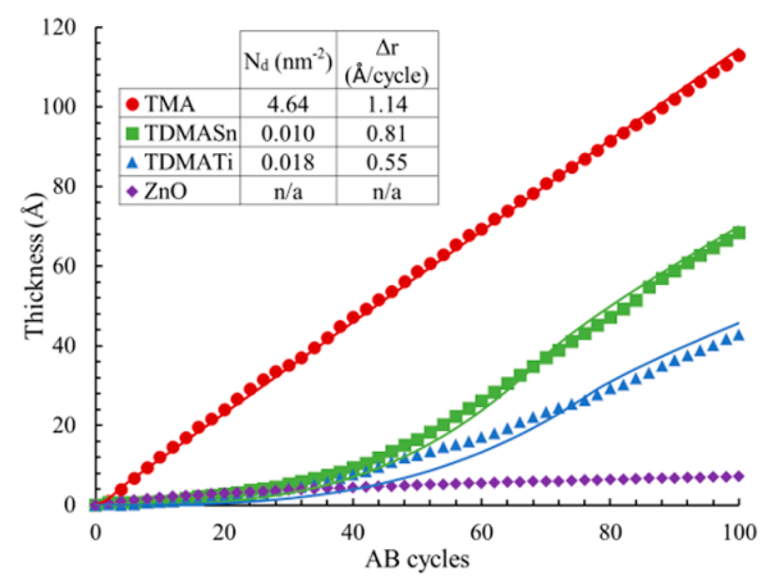

Figure 5. Mass gain, converted to equivalent film thickness, versus cycle number for several common oxide ALD processes on vaporloaded $\mathrm{C}_{12} \mathrm{SH}$ on $\mathrm{Au}$ at $125{ }^{\circ} \mathrm{C}$. See Figure 6 for DEZ model fit. The uninhibited ALD growth of TMA, TDMASn, and TDMATi with water is $1.1,0.8$, and $0.6 \AA$ /cycle, respectively, as measured by ex situ ellipsometry.

The TMA- $\mathrm{H}_{2} \mathrm{O}$ process shows almost no inhibition, as expected for a precursor that has the ability to displace the alkanethiol at temperatures above $60{ }^{\circ} \mathrm{C} .^{36}$ TDMATi (blue up triangles) and TDMASn (green squares) both show relatively small $N_{\mathrm{d}}\left(1 \times 10^{-2} \mathrm{~nm}^{-2}\right)$. These precursors have nearly identical structures that results from four amido ligands that surround the central metal. Although this sample set is too small to isolate the effect of metal chemistry, that they show somewhat disparate nucleation densities suggest differences in reactivity of the core metal. ${ }^{24}$ Perhaps most strikingly, Figure 5 reveals a significantly longer inhibition of $\mathrm{ZnO}$ growth (and a small initial mass gain) under conditions of optimal $\mathrm{C}_{12} \mathrm{SH}$ vapor-loading. Like TMA, DEZ has alkyl ligands, but differs in its reactivity with alkanethiols. DEZ also exhibits a more linear structure than any of the other precursors. One alternative explanation for these data is that nucleation occurs with equal density within the SAM, but that the resulting hybrid SAM (comprising both alkanethiol and metal precursor) impedes further growth of these nuclei. For precursors that may be more easily integrated into an alkanethiol SAM, namely DEZ, a synergistic effect in the form of a "hybrid" SAM may be induced that results in an unusually long inhibition of coalesced film growth. This study highlights the in situ QCM approach as one well-suited to survey with high speed and resolution the inhibition efficacy of a particular SAM for a selected ALD process. Furthermore, the $\mathrm{C}_{12} \mathrm{SH}$ SAM on $\mathrm{Au}$ is identified as a broadly applicable route to inhibiting several oxide ALD processes.

An expanded trace of DEZ- $\mathrm{H}_{2} \mathrm{O}$ cycles reveals a $\sim 100$ cycle inhibition of $\mathrm{ZnO}$ growth after a small initial mass gain, Figure 6. The relatively small mass gain during the first 100 cycles might be explained by DEZ uptake during early ALD cycling, suggesting that a DEZ- $\mathrm{C}_{12} \mathrm{SH}$ "hybrid" SAM may inhibit further nucleation and growth. See Figure S5 in the Supporting 


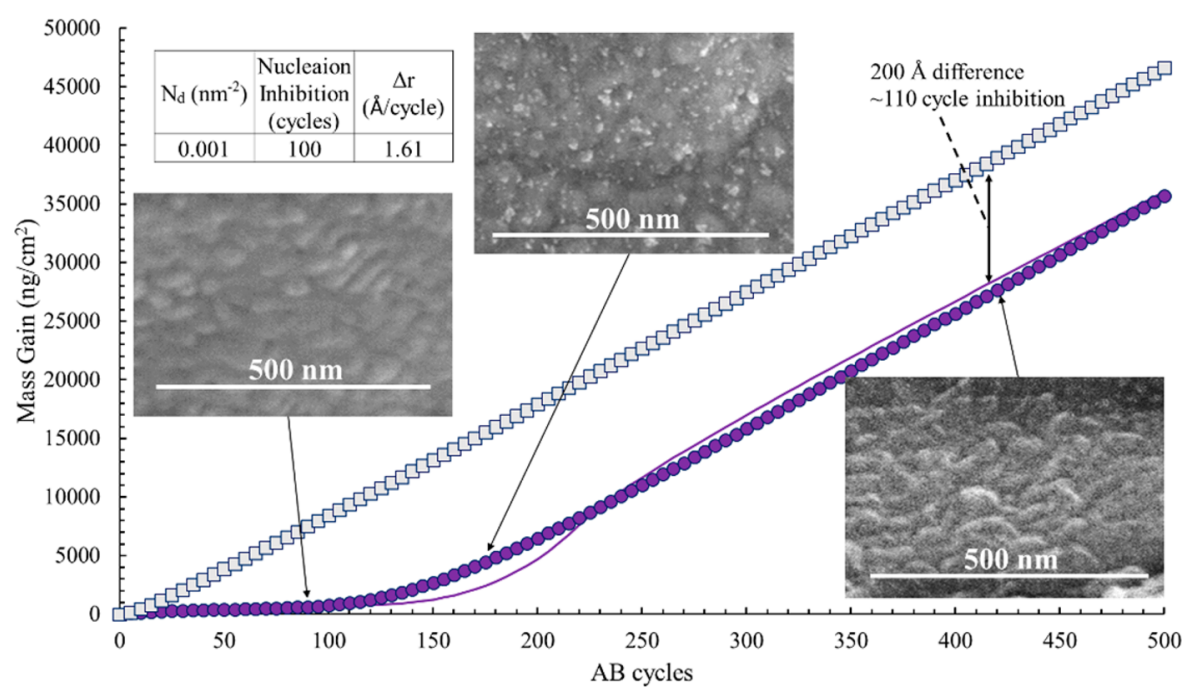

Figure 6. Growth of $\mathrm{ZnO}$ on vapor-loaded $\mathrm{C}_{12} \mathrm{SH}$ at $125^{\circ} \mathrm{C}$ on $\mathrm{Au}$ (purple circles) and $\mathrm{Al}_{2} \mathrm{O}_{3}$ coated (gray squares) AT QCM crystals. The bare Au QCM crystal was in the front QCM position while the $\mathrm{Al}_{2} \mathrm{O}_{3}$ coated QCM crystal was in the back position. Approximately 100 standard ZnO ALD cycles occur before growth equivalent to one $\mathrm{ZnO} A L D$ cycle is observed. SEM images from a nominally identical experiment that were aborted during complete blocking (left), breakthrough (center), and after continuous film growth (right). EDS confirms the presence of Zn in the right image. Growth of $\mathrm{ZnO}$ using $\mathrm{DEZ}$ and water is $1.7 \AA$ /cycle as determined by ellipsometry.

Information for a zoom-in view of the raw QCM trace of Figure 6. This result was corroborated on three separate depositions on a total of 8 crystals, each showing strong inhibition for at least 100 cycles but sometimes as long as 400 cycles. Normal nucleation and growth of $\mathrm{ZnO}$ on control samples was observed simultaneously with and adjacent to SAM-loaded samples that display inhibition behavior. One control was a QCM crystal coated with 50 cycles of $\mathrm{Al}_{2} \mathrm{O}_{3}(\sim 6 \mathrm{~nm})$ to ensure no surface poisoning from the $\mathrm{C}_{12} \mathrm{SH}$ SAM since $\mathrm{Al}_{2} \mathrm{O}_{3}$ surfaces show virtually no binding affinity for thiols. ${ }^{37}$ From the QCM trace on $\mathrm{Al}_{2} \mathrm{O}_{3}$ it is clear that there is no inhibition to the growth of $\mathrm{ZnO}$ after $\mathrm{C}_{12} \mathrm{SH}$ treatment, confirming that no physisorbtion is occurring in the $\mathrm{C}_{12} \mathrm{SH}$ vapor loading process. A series of $\mathrm{Si}$ witness substrates coated with either 50 cycles of $\mathrm{Al}_{2} \mathrm{O}_{3}$ or with thermally deposited $\mathrm{Au}$ were also included in the same deposition. After 700 cycles of $\mathrm{ZnO}$ deposition the Aucoated witness samples showed an overall $\mathrm{ZnO}$ thickness, measured by ellipsometry, of 1088 and $1057 \AA$ near the front and back QCM positions, respectively. In contrast, $\mathrm{Al}_{2} \mathrm{O}_{3}$ coated Si samples showed $\mathrm{ZnO}$ thickness of 1176 and $1197 \AA$ near the same positions, respectively. With this information, we can estimate the minimum number of ALD cycles that must have passed prior to establishing the full ALD growth rate by assuming the same full (linear) growth rate as measured by the adjacent $\mathrm{Al}_{2} \mathrm{O}_{3}$-coated $\mathrm{Si}$ witnesses. In so doing, we measure a 88 and $140 \AA$ difference for the front and back $A u$ substrates, respectively, relative to the $\mathrm{Al}_{2} \mathrm{O}_{3}$-coated $\mathrm{Si}$ in the same reactor position. These thicknesses correspond to an inhibition of at least $\sim 52$ and $\sim 82$ cycles for the upstream and downstream reactor positions, respectively. These are minimum values derived from a step function, which is unlikely considering the multicycle ramp up to the full growth rate observed in all QCM data. Still the values are comparable to the $\sim 110$ cycle inhibition shown by the QCM trace in Figure 6. They also serve to illustrate the sensitivity (to $\mathrm{Au}$ preparation for example) with which $\mathrm{ZnO}$ inhibition is occurring under the process conditions reported here. Further discussion of the in situ control can be found in the Supporting Information.
The insets of Figure 6 display SEM images at various stages of nominally identical depositions. The ex situ images corroborate the in situ evidence for little to no growth during the initial stages of metal oxide ALD cycling (insert left). The image is visually identical to a bare Au QCM crystal and also shows no $\mathrm{Zn}$ by EDS. The second image (insert center) was captured on a crystal for which the QCM trace starts to show some mass gain but has yet to reach the full $\mathrm{ZnO}$ ALD growth rate. An array of $\mathrm{ZnO}$ particles (bright white spots in the image) is observed with spatial density of order $\sim 1 \times 10^{-3}$ $\mathrm{nm}^{-2}$. This is in reasonable agreement with the model fit to the in situ measurement shown in Figure 6, which suggests an $N_{\mathrm{d}}$ value of $1 \times 10^{-3} \mathrm{~nm}^{-2}$. In the steady mass addition regime the inset right image reveals a roughened surface completely coated with crystalline $\mathrm{ZnO}$. The EDS spectrum (see Figure S6 in the Supporting Information) and SEM image confirm the presence of $\mathrm{Zn}$ and point to a coalesced-island morphology that now consists of a continuous thin film. We hypothesize that the $\mathrm{C}_{12} \mathrm{SH}$ SAM is only slightly perturbed and largely buried beneath the continuous metal oxide film as illustrated schematically in Figure 1. The fate of the SAM and its most common failure mechanisms in this intriguing system are the subject of future investigations to be carried out with the aid of in situ FTIR and mass spectrometry.

In light of the insights gleaned from this novel and highresolution approach, our hypothesis for the mechanism of nucleation of ALD oxides on SAMs remains defect/pinhole formation but with the caveat that in some special cases ALD precursors might be incorporated to become an integral part of the SAM. The unusually large inhibition of normal $\mathrm{ZnO}$ ALD may point the way to new strategies for SAM defect amelioration.

\section{CONCLUSION}

In summary, we demonstrate a time-efficient and highresolution method to analyze in situ the deposition dynamics of ALD on SAMs on a cycle-by-cycle basis. An analytical island growth model is applied to qualify the appropriateness of the model and, when well fit, quantify the inhibition and nucleation 
density of several metal oxide ALD processes as a function of growth temperature and precursor chemistry. The approach allows the detailed investigation of a model SAM system, alkanethiol on $\mathrm{Au}$-loaded by either solution or vapor-phase methods. Compared to previous reports of SAM-based inhibition, $\mathrm{C}_{12} \mathrm{SH}$ on $\mathrm{Au}$ is shown to be effective at inhibiting ALD oxides generally. Based on these studies, we find further evidence to support a defect/pinhole mechanism that in at least one case points to an unexpected dependence on ALD precursor choice. This work provides insight into the improvement of area-selective ALD of metal oxides and presents a in situ method to understand its subtleties.

\section{ASSOCIATED CONTENT}

\section{S Supporting Information}

Additional analytic model information, contact angle and ellipsometry values, EDS/SEM scans, and QCM traces. This material is available free of charge via the Internet at http:// pubs.acs.org/

\section{AUTHOR INFORMATION}

\section{Corresponding Author}

*E-mail: martinson@anl.gov.

\section{Author Contributions}

All authors have given approval to the final version of the manuscript.

\section{Notes}

The authors declare no competing financial interest.

\section{ACKNOWLEDGMENTS}

This work was supported as part of the ANSER Center, an Energy Frontier Research Center funded by the U.S. Department of Energy, Office of Science, Office of Basic Energy Sciences, under Award DE-SC0001059. A portion of the research was performed at Argonne National Laboratory, a U.S. Department of Energy, Office of Science, Laboratory operated under Contract DE-AC02-06CH11357 by UChicago Argonne, LLC. Addition electron microscopy was performed in the EPIC and KECKII facilities of the NUANCE Center at Northwestern University. The NUANCE center is supported by NSFNSEC, NSF-MRSEC, the KECK Foundation, the state of Illinois, and Northwestern University.

\section{ABBREVIATIONS}

ALD, atomic layer deposition

SAM, self-assembled monolayers

QCM, quartz crystal microbalance

SEM, scanning electron microscope

$\mathrm{C}_{12} \mathrm{SH}$, 1-dodecancethiol

DEZ, diethylzinc

TMA, trimethylaluminum

TDMATi, tetra(dimethylamido)titanium

\section{REFERENCES}

(1) George, S. M. Atomic Layer Deposition: An Overview. Chem. Rev. 2010, 110, 111-31.

(2) Puurunen, R. L. Surface Chemistry of Atomic Layer Deposition: A Case Study for the Trimethylaluminum/Water Process. J. Appl. Phys. 2005, 97, 121301.

(3) Kim, H.; Lee, H.-B.-R.; Maeng, W.-J. Applications of Atomic Layer Deposition to Nanofabrication and Emerging Nanodevices. Thin Solid Films 2009, 517, 2563-2580.
(4) Xu, Y.; Musgrave, C. A DFT Study of the Al2O3 Atomic Layer Deposition on SAMs: Effect of SAM Termination. Chem. Mater. 2004, 646-653.

(5) Färm, E.; Kemell, M.; Ritala, M.; Leskelä, M. Self-Assembled Octadecyltrimethoxysilane Monolayers Enabling Selective-Area Atomic Layer Deposition of Iridium. Chem. Vap. Deposition 2006, $12,415-417$.

(6) Park, K. J.; Doub, J. M.; Gougousi, T.; Parsons, G. N. Microcontact Patterning of Ruthenium Gate Electrodes by Selective Area Atomic Layer Deposition. Appl. Phys. Lett. 2005, 86, 051903.

(7) Jiang, X.; Bent, S. F. Area-Selective ALD with Soft Lithographic Methods: Using Self-Assembled Monolayers to Direct Film Deposition. J. Phys. Chem. C 2009, 113, 17613-17625.

(8) Färm, E.; Kemell, M.; Ritala, M.; Leskelä, M. Selective-area Atomic Layer Deposition with Microcontact Printed Self-assembled Octadecyltrichlorosilane Monolayers as Mask Layers. Thin Solid Films 2008, 517, 972-975.

(9) Elam, J.; Zinovev, A.; Pellin, M.; Comstock, D. J.; Hersam, M. Nucleation and Growth of Noble Metals on Oxide Surfaces using Atomic Layer Deposition. ECS Trans. 2007, 3, 271-278.

(10) Lee, H.-B.-R.; Mullings, M. N.; Jiang, X.; Clemens, B. M.; Bent, S. F. Nucleation-Controlled Growth of Nanoparticles by Atomic Layer Deposition. Chem. Mater. 2012, 24, 4051-4059.

(11) Färm, E.; Vehkamäki, M.; Ritala, M.; Leskelä, M. Passivation of Copper Surfaces for Selective-area ALD using a Thiol Self-assembled Monolayer. Semicond. Sci. Technol. 2012, 27, 074004.

(12) Park, M. H.; Jang, Y. J.; Sung-Suh, H. M.; Sung, M. M. Selective Atomic Layer Deposition of Titanium Oxide on Patterned Selfassembled Monolayers Formed by Microcontact Printing. Langmuir 2004, 20, 2257-60.

(13) George, A.; Knez, M.; Hlawacek, G.; Hagedoorn, D.; Verputten, H. H. J.; van Gastel, R.; ten Elshof, J. E. Nanoscale Patterning of Organosilane Molecular Thin Films from the Gas Phase and its Applications: Fabrication of Multifunctional Surfaces and Large Area Molecular Templates for Site-selective Material Deposition. Langmuir 2012, 28, 3045-52.

(14) Dube, A.; Sharma, M.; Ma, P. F.; Ercius, P. A.; Muller, D. A.; Engstrom, J. R. Effects of Interfacial Organic Layers on Nucleation, Growth, and Morphological Evolution in Atomic Layer Thin Film Deposition. J. Phys. Chem. C 2007, 111, 11045-11058.

(15) Chen, R.; Kim, H.; McIntyre, P. C.; Bent, S. F., Self-assembled Monolayer Resist for Atomic Layer Deposition of $\mathrm{HfO}_{2}$ and $\mathrm{ZrO}_{2}$ High- $\kappa$ Gate Dielectrics. In Appl. Phys. Lett., 2004; Vol. 84, p 4017.

(16) Chen, R.; Kim, H.; McIntyre, P. C.; Bent, S. F. Investigation of Self-Assembled Monolayer Resists for Hafnium Dioxide Atomic Layer Deposition. Chem. Mater. 2005, 17, 536-544.

(17) Wind, R. A.; George, S. M. Quartz Crystal Microbalance Studies of Al2O3 Atomic Layer Deposition using trimethylaluminum and water at 125 degrees C. J. Phys. Chem. A 2010, 114, 1281-9.

(18) Seo, E. K.; Lee, J. W.; Sung-Suh, H. M.; Sung, M. M. Atomic Layer Deposition of Titanium Oxide on Self-Assembled-MonolayerCoated Gold. Chem. Mater. 2004, 16, 1878-1883.

(19) Kobayashi, N. P.; Donley, C. L.; Wang, S.-Y.; Williams, R. S. Atomic Layer Deposition of Aluminum Oxide on Hydrophobic and Hydrophilic Surfaces. J. Cryst. Growth 2007, 299, 218-222.

(20) Preiner, M. J.; Melosh, N. A. Identification and Passivation of Defects in Self-assembled Monolayers. Langmuir 2009, 25, 2585-7.

(21) Lu, J.; Stair, P. C. Nano/Subnanometer Pd Nanoparticles on Oxide Supports Synthesized by AB-type and Low-temperature ABCtype Atomic Layer Deposition: Growth and Morphology. Langmuir 2010, 26, 16486-95.

(22) Riha, S. C.; Libera, J. A.; Elam, J. W.; Martinson, A. B. F. Design and Implementation of an Integral Wall-mounted Quartz Crystal Microbalance for Atomic Layer Deposition. Rev. Sci. Instrum. 2012, 83, 094101.

(23) Love, J. C.; Estroff, L. A.; Kriebel, J. K.; Nuzzo, R. G.; Whitesides, G. M. Self-assembled Monolayers of Thiolates on Metals as a Form of Nanotechnology. Chem. Rev. 2005, 105, 1103-69. 
(24) Elam, J. W.; Baker, D. A.; Hryn, A. J.; Martinson, A. B. F.; Pellin, M. J.; Hupp, J. T. Atomic Layer Deposition of Tin Oxide Films using Tetrakis(dimethylamino) Tin. J. Vac. Sci. Technol., A 2008, 26, 244.

(25) Xie, Q.; Musschoot, J.; Deduytsche, D.; Van Meirhaeghe, R. L.; Detavernier, C.; Van den Berghe, S.; Jiang, Y.-L.; Ru, G.-P.; Li, B.-Z.; $\mathrm{Qu}$, X.-P. Growth Kinetics and Crystallization Behavior of $\mathrm{TiO}_{2}$ Films Prepared by Plasma Enhanced Atomic Layer Deposition. J. Electrochem. Soc. 2008, 155, H688.

(26) Nilsen, O.; Mohn, C. E.; Kjekshus, A.; Fjellvåg, H. Analytical Model for Island Growth in Atomic Layer Deposition using Geometrical Principles. J. Appl. Phys. 2007, 102, 024906.

(27) Biercuk, M. J.; Monsma, D. J.; Marcus, C. M.; Becker, J. S.; Gordon, R. G. Low-temperature Atomic-Layer-Deposition lift-off Method for Microelectronic and Nanoelectronic Applications. Appl. Phys. Lett. 2003, 83, 2405.

(28) Park, N. G.; J, V. D. L.; Frank, A. J. Comparison of Dyesensitized Rutile-and Anatase-based $\mathrm{TiO}_{2}$ solar cells. J. Phys. Chem. B 2000, 104, 8989-8994.

(29) Schuisky, M.; Hårsta, A.; Aidla, A. Atomic Layer Chemical Vapor Deposition of $\mathrm{TiO}_{2}$ Low Temperature Epitaxy of Rutile and Anatase. J. Electrochem. Soc. 2000, 147, 3319-3325.

(30) King, D. Oxidation of Gold by Ultraviolet Light and Ozone at 25 C. J. Vac. Sci. Technol., A 1995, 13, 1247-1253.

(31) Vericat, C.; Vela, M. E.; Benitez, G.; Carro, P.; Salvarezza, R. C. Self-assembled Monolayers of Thiols and Dithiols on Gold: New Challenges for a Well-known System. Chem. Soc. Rev. 2010, 39, 180534.

(32) Aarik, J.; Aidla, A.; Mändar, H.; Sammelselg, V. Anomalous Effect of Temperature on Atomic Layer Deposition of Titanium Dioxide. J. Cryst. Growth 2000, 220, 531-537.

(33) Elam, J.; George, S. Growth of $\mathrm{ZnO} / \mathrm{Al}_{2} \mathrm{O}_{3}$ Alloy Films using Atomic Layer Deposition Techniques. Chem. Mater. 2003, 10201028.

(34) Yousfi, E.; Fouache, J.; Lincot, D. Study of Atomic Layer Epitaxy of Zinc Oxide by in-situ Quartz Crystal Microgravimetry. Appl. Surf. Sci. 2000, 153, 223-234.

(35) Herrmann, C. F.; DelRio, F. W.; Bright, V. M.; George, S. M. Conformal Hydrophobic Coatings Prepared using Atomic Layer Deposition Seed Layers and Non-chlorinated Hydrophobic Precursors. J. Micromech. Microeng. 2005, 15, 984-992.

(36) Elam, J.; Libera, J.; Huynh, T.; Feng, H.; Pellin, M. J. Atomic Layer Deposition of Aluminum Oxide in Mesoporous silica gel. J. Phys. Chem. C 2010, 114, 17286-17292.

(37) Rodriguez, J. A.; Hrbek, J. Interaction of Sulfur with WellDefined Metal and Oxide Surfaces: Unraveling the Mysteries behind Catalyst Poisoning and Desulfurization. Acc. Chem. Res. 1999, 32, 719-728. 